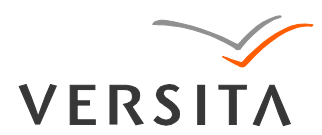

GEOCHRONOMETRIA 39(1) 2012: 57-61

DOI 10.2478/s13386-011-0051-4

Available online at

www.springerlink.com

\title{
LUMINESCENCE AGE CONSTRAINTS ON PALAEO-EARTHQUAKE EVENTS ALONG THE LINGWU FAULT IN THE YINCHUAN BASIN, CHINA
}

\author{
WANG XULONG ${ }^{1}$, CHAI CHIZHANG ${ }^{2}$, DU PENG ${ }^{2}$, LEI QIYUN ${ }^{2}$, YIN GONGMING ${ }^{3}$ and LU YANCHOU ${ }^{3}$ \\ ${ }^{I} S K L L Q G$, Institute of Earth Environment, CAS, Xi'An 710075, China \\ ${ }^{2}$ Seismological Bureau of Ningxia Hui Autonomous Region, Yinchuan 750001, China \\ ${ }^{3}$ SKLED, Institute of Geology, China Seismological Bureau, Beijing 100029, China
}

Received 29 November 2010

Accepted 5 August 2011

\begin{abstract}
Optically stimulated luminescence (OSL) dating was applied to sediment samples in order to provide age constraints on the palaeo-earthquake events that are recorded in a trench on the Lingwu fault near Yinchuan on the northeastern margin of the Tibetan Plateau, China. Combining seventeen OSL ages with field observations in the trench shows that at least four events took place at this specific site, and that this fault has been active over the past $200 \mathrm{ka}$.
\end{abstract}

Keywords: Palaeo-earthquake, OSL dating, Yinchuan basin.

\section{INTRODUCTION}

The Yinchuan Basin is within the northeastern margin of the Tibetan Plateau and is one of the grabens around the Ordos block, which forms the major tectonic feature of the late Cenozoic extension in north China (Zhang et al., 1998). The Yinchuan graben is a trending NNE-SSW basin of Cenozoic Era, with a width of $50-55 \mathrm{~km}$ eastwest and a length of about $160 \mathrm{~km}$ north-south (Fig. 1).

In the Yinchuan Basin and surrounding area (105.8-106.8E, 38-38.8N) twenty two earthquakes with magnitude $M>4.0$ have been recorded since 1970 (Data from http://www.csndmc.ac.cn). The historical record of destructive earthquakes in the Yinchuan graben dates back to $1010 \mathrm{AD}$ (Gu et al., 1989). Fifteen earthquakes with a magnitude of M 5 or more have occurred in this region since $1010 \mathrm{AD}$; one was $\sim \mathrm{M} 8$, three were $\sim \mathrm{M} 6$, and eleven were $\sim$ M 5. A set of faults, some trending

Corresponding author: X.L. Wang

e-mail:wxl@loess.llqg.ac.cn northeast, others trending northwest, and a few trending east, both outline and disrupt the Yinchuan graben. Previous studies have discovered and confirmed the presence of four large-scale active faults, namely Helanshan East fault, Luhuatai fault, Yinchuan fault and Yellow River fault (Fig. 1). Here we focus on the Yellow River fault, also named the north segment of the Lingwu fault (Fig. 1) by Liao et al. (2000) and Chai et al. (2001).

\section{LINGWU FAULT AND TRENCH DESCRIPTION}

The Lingwu fault is located about $10 \mathrm{~km}$ east of Yongning to the south of Yinchuan (Fig. 1), at the eastern border of the Yinchuan basin; the Lingwu fault forms the boundary area between the Yinchuan Basin and the Ordos Platform. The Lingwu normal fault is about $48 \mathrm{~km}$ in length with the strike direction being $40^{\circ}$ and the inclination angle being $70^{\circ}$. In 2005 the Shuangchagou trench was excavated in the middle of the Lingwu fault to reveal the past activity of this fault. In 2007 we cleaned this 


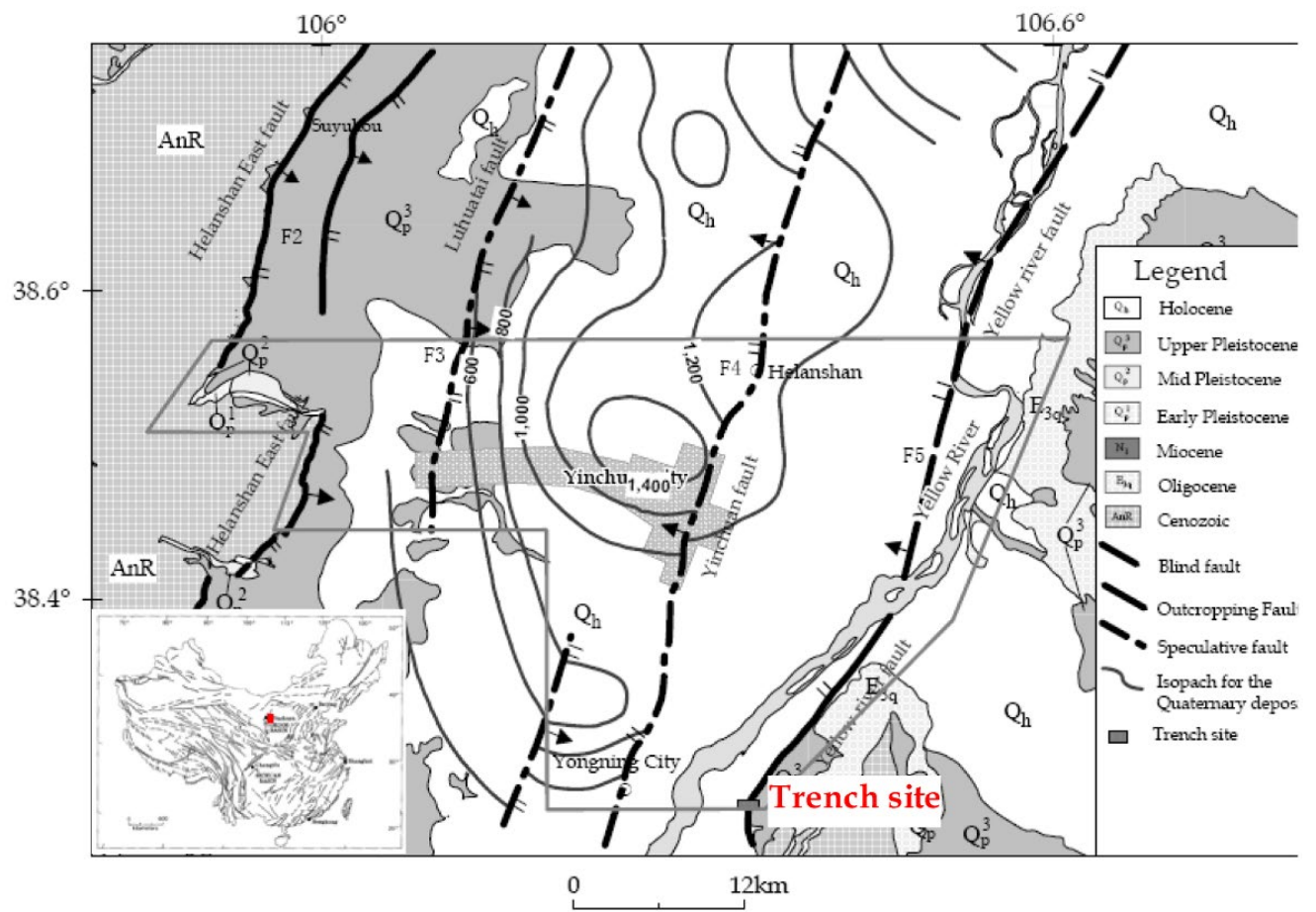

Fig. 1. Map showing pattern of faults in the Yinchuan Basin and its location in China (inset).

trench and collected sediment samples to provide age constraints for palaeo-earthquake events in the late Quaternary. Fig. 2A is a photograph of this section of the trench, and Fig. 2B is a log from the fieldwork in 2007 showing the location of the samples taken for OSL dating. The exposed strata are composed of silt, silty clay, sandy clay and gravel, interpreted as piedmontfluvial/alluvial and aeolian facies. In addition, two faults (f1 and $\mathrm{f} 2$ ) and three infilled wedges (A, B and C) could be seen (Fig. 2B). On the basis of the lithology, colour, hue, grain size and structure, 9 units are identified (Fig. 2B), and are described below:

Unit 1: light greyish brown silt, mostly aeolian, bedding along the slope at the top, $30-40 \mathrm{~cm}$ thick, gravels with calcium carbonate film on the top of the east side, gravel size ranging from $2-10 \mathrm{~cm}$, roundness ranging from subangular to rounded.

Unit 2: lens like, light greyish brown silt, gravel at the bottom, visible bedding, observed only on the top of $\mathrm{f} 2$.

Unit 3: light greyish brown silt, blocky structure, no bedding, lower boundary unclear, aeolian in origin. Medium-fine gravel layer deposited along the slope at the bottom of the east side, diagnostic of the lower filling wedge B. It is $1 \mathrm{~m}$ thick.

Unit 4: silt and pluvial/alluvial gravel, upper boundary not distinct. Found on both sides of the fault, coarse to the east and fine to the west.

4a is grayish aeolian silt, no bedding, only found west of $\mathrm{fl}$, and is related to the latest activity of $\mathrm{fl}$; it is $50-70 \mathrm{~cm}$ thick.
$4 \mathrm{~b}$ is mostly grey, includes some purple and greyishgreen coarse-grained gravel, and is interpreted as pluvial. Lithology of the gravels includes quartz sandstone and cherty limestone, with moderate roundness, ranging from subangular to rounded. Horizontal bedding.

$4 \mathrm{c}$, similar to $4 \mathrm{a}$, is aeolian silt, $10-20 \mathrm{~cm}$ thick, sandwiched between two gravel layers, and is a stratigraphic marker on both sides of $\mathrm{fl}$.

$4 \mathrm{~d}$. similar to $4 \mathrm{~b}$, is a gravel layer. Coarse on both east and west, some medium-small gravel in the middle, horizontal bedding at the east, and sloping bedding developed in the middle, slope angle is around $30^{\circ}$.

Unit 5: only found on the west side, greyish silt, contains medium-coarse gravel, same lithology as $4 \mathrm{~b}$. Distinct bedding, interpreted as talus deposits after the first displacement of $\mathrm{f} 2,1 \mathrm{~m}$ thick.

Unit 6: secondary light red clay, massive, no bedding, mixed with grey fine silt aggregates and medium-small gravel near f2, is rapid colluvial debris flow deposits after fault dislocation. Top part was eroded by running water; reworking of Unit 7.

Unit 7: Secondary red earth, greyish and pink, yellowish in some parts, compact, includes tiny stems and leaves, waterlain deposit, developed on both sides of $\mathrm{fl}$, $50 \mathrm{~cm}$ on the west and $15-20 \mathrm{~cm}$ on the east. This suggests that displacement of $\mathrm{fl}$ occurred before this stratum was laid down, and thus the layers are lower and thicker on the west and higher and thinner on the east. 


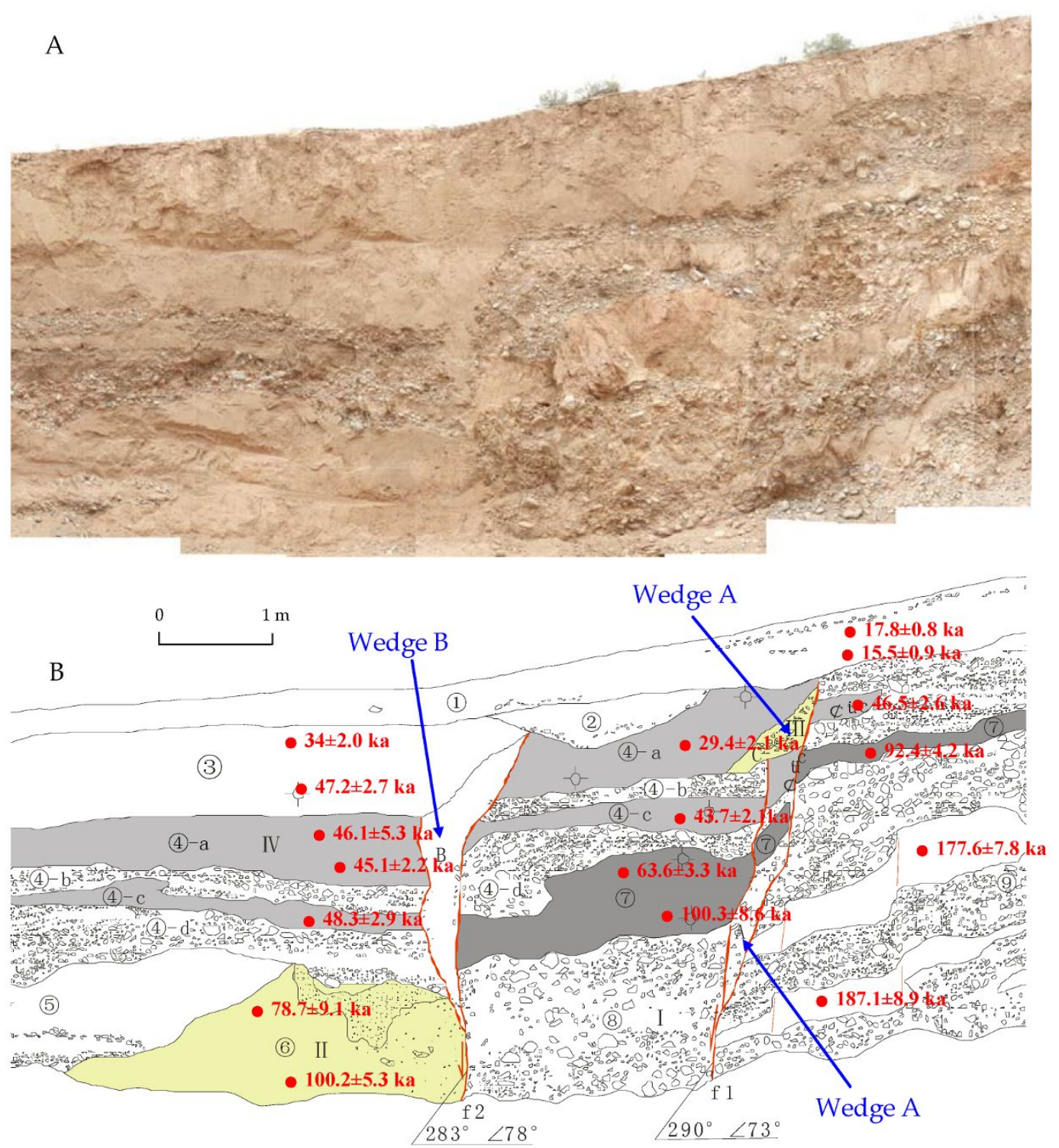

Fig. 2. (A) Orthorectified mosaic of $1 \times 1 \mathrm{~m}$ photographs showing the stratified units of the north wall of the Shuangchagou trench and (B) schematic section showing sedimentary units (1 to 9), faults f1 and f2, collapse wedges I, II and II, and filled wedges A and B along faults f1 and f2, together with sample locations and OSL ages.

Unit 8: coarse-grained gravel, contains greyish silt and clay, composition is the same as unit 9 , bedding was disturbed, indicating dislocation.

Unit 9: greyish coarse gravel, contains sandy clay and a small amount of purple gravel, mostly quartz sandstone and cherty sandstone, gravel size is $2-10 \mathrm{~cm}$, has a maximum thickness of $20 \mathrm{~cm}$, contains 3 layer of sandy clay lenses, gravel stratification is clear, gravel roundness is moderate, ranging from subangular to rounded.

These nine units were used to define three collapse wedges (shown as I, II and II in Fig. 2B) which relate to palaeo-earthquake events recorded at this site.

In addition, tectonically formed wedges (A and $\mathrm{B}$, relating to faults $\mathrm{fl}$ and $\mathrm{f} 2$, respectively) and a colluvial wedge $(\mathrm{C})$ can be seen in this section (Fig. 2B). Wedge A is mostly composed of silt, and gravels are imbricated near the fault. Wedge B is composed of gravel and silt. Wedge $\mathrm{C}$ is mostly composed of gravel.

\section{OSL DATING}

OSL dating of quartz grains was selected as the most appropriate luminescence method for dating these deposits which are primarily of aeolian origin and contain abundant quartz. The quartz OSL signal was previously used by Fattahi et al. (2010) in their study of recent earthquake activity along a fault in Iran. 


\section{Samples and instruments}

17 samples were collected from the Shuangchagou trench. In the laboratory, fine-grained (4-11 $\mu \mathrm{m})$ quartz was extracted by the sample pretreatment that was used for Luochuan loess (Lu et al., 2007).

All measurements were performed using a Daybreak 2200 automated OSL reader equipped with a combined blue $(470 \pm 5 \mathrm{~nm})$ and infrared $(880 \pm 80 \mathrm{~nm})$ LED optical stimulation unit, and a ${ }^{90} \mathrm{Sr} /{ }^{90} \mathrm{Y}$ beta source $(0.138 \mathrm{~Gy} / \mathrm{s})$ for irradiations. All luminescence measurements were made at $125^{\circ} \mathrm{C}$ for $50 \mathrm{~s}$ with both IR and blue stimulation powers at $\sim 45 \mathrm{~mW} / \mathrm{cm}^{2}$. Luminescence emissions were detected by an EMI 9235QA photomultiplier tube and two $3 \mathrm{~mm}$ U-340 glass filters. A typical OSL decay curve is shown in the inset to Fig. 3A; it is much more intense than the signals presented by Fattahi et al. (2010). For $\mathrm{D}_{\mathrm{e}}$ calculation, the first $5 \mathrm{~s}$ integral of the OSL decay curve was used after subtracting the integrated counts for the last $5 \mathrm{~s}$. Bleaching was provided by a solar simulator (SOL2) and the exposure time was $180 \mathrm{~s}$.
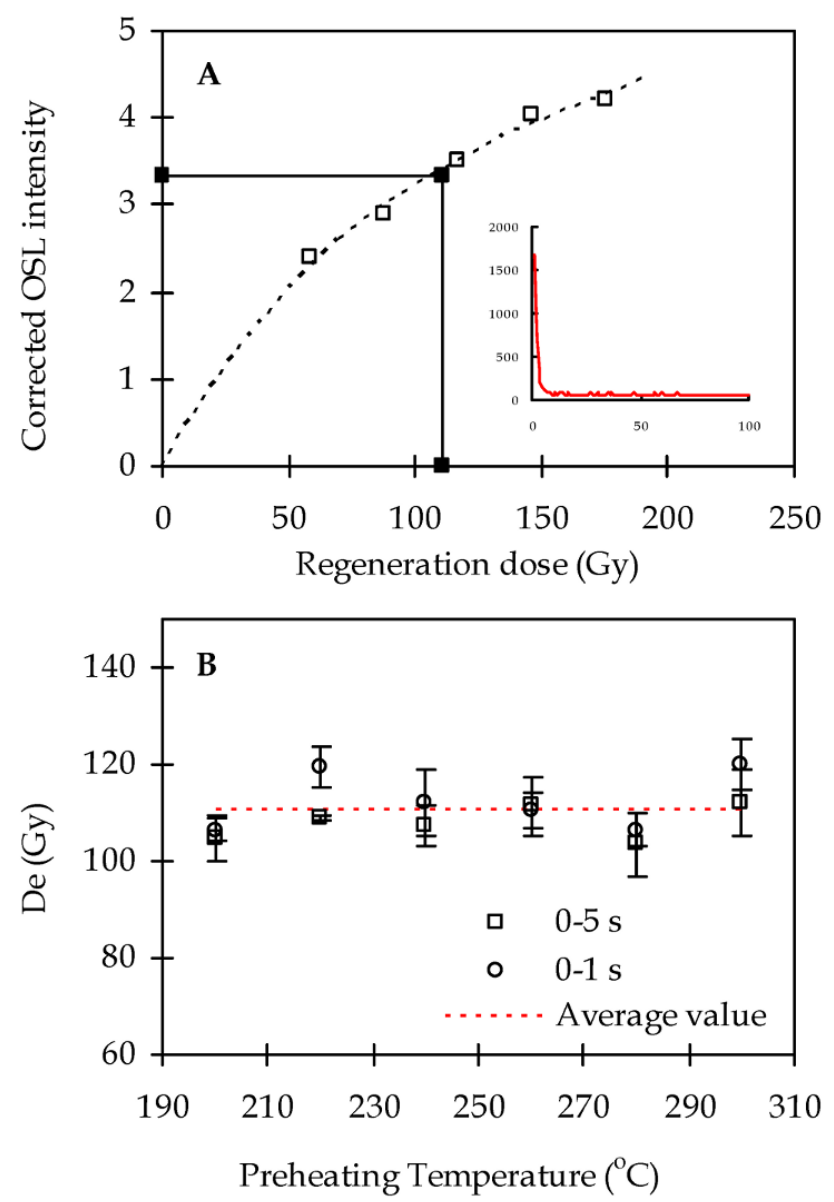

Fig. 3. $D_{e}$ determination for sample IEE1905. (A) multiple aliquot, regenerative dose response curve and OSL decay curve (inset). (B) $D_{e}$ as a function of preheat temperature for two signal integral regions.

\section{$D_{\mathrm{e}}$ determination}

$\mathrm{D}_{\mathrm{e}}$ values were determined by the multiple-aliquot regenerative dose protocol (Lu et al., 2007). For each sample, nine natural aliquots were measured and the OSL sensitivity was monitored by the response to a test dose. The average natural sensitivity-corrected OSL intensity was compared with the dose response curve constructed using six regenerative doses given after a $180 \mathrm{~s}$ exposure to the SOL2 light source (Fig. 3A). Sample IEE1905 (sample from unit $4 \mathrm{c}$ with an age of $29.4 \pm 2.1 \mathrm{ka}$ in Fig. 2B) was used to determine the preheating temperature for the dating protocol. Fig. 3B shows that a broad plateau was obtained for this sample when using either the first $1 \mathrm{~s}$ or the first $5 \mathrm{~s}$ integral of the OSL decay curve, especially for preheating temperatures of 240 and $260^{\circ} \mathrm{C}$. This indicates that the fine-grained quartz used in this study had been well bleached before deposition and was thus suitable for OSL dating, thus supporting the field observation that most of the samples had aeolian origin. A preheat at $260^{\circ} \mathrm{C}$ for $10 \mathrm{~s}$ was applied to all samples from this trench, and the $\mathrm{D}_{\mathrm{e}}$ values determined for the 17 finegrained quartz samples are given in Table 1.

\section{Dose rate and OSL ages}

The U, Th, and $\mathrm{K}$ contents were measured by inductively-coupled mass spectrometry in the Geology Department of Royal Holloway, University of London, and the values are given in Table 1. In the dose rate calculation, the error associated with each of these values was assumed to be $\pm 5 \%$. The alpha values were assumed to be $0.04 \pm 0.01$ for fine-grained quartz (Rees-Jones, 1995). The dose rate for each sample is calculated directly by using the observed radionuclide concentrations, and the water content is assumed to be $5 \pm 3 \%$; an assumed value was used as the OSL samples were collected two years after the trench had been excavated and thus the present day values would not have been relevant for the burial period. The dose rates are given in Table 1 and are similar for all samples, ranging from 3.03 to $3.82 \mathrm{~Gy} / \mathrm{ka}$. The OSL ages are given in Table $\mathbf{1}$ and are shown in Fig. 2B, where they can be seen to make stratigraphic sense, again confirming that the grains were well bleached at deposition.

\section{DISCUSSION}

On the basis of the geological settings and the luminescence dating results, four paleo-earthquake events can be recognized in this trench.

Event 1 happened along f1, resulting in the collapse wedge I (Unit 8). Thus Event 1 happened after the deposition of Unit 9, but before Unit 8. The OSL ages show that the event happened between $177.6 \pm 7.8 \mathrm{ka}$ and $100.3 \pm 8.6 \mathrm{ka}$. 
X. L. Wang et al.

Table 1. Element concentrations, dose rates, $D_{e}$ values and OSL ages for each sample identified in Fig. 2B.

\begin{tabular}{cccccccc}
\hline Lab No & Field No. & $\begin{array}{c}\mathbf{U} \\
(\mathbf{p p m})\end{array}$ & $\begin{array}{c}\text { Th } \\
(\mathbf{p p m})\end{array}$ & $\begin{array}{c}\mathrm{K} \\
(\%)\end{array}$ & $\begin{array}{c}\text { Dose rate } \\
(\mathbf{G y / k a})\end{array}$ & \multicolumn{1}{c}{$\begin{array}{c}\mathbf{D}_{\mathrm{e}} \\
(\mathbf{G y})\end{array}$} & $\begin{array}{c}\text { Age } \\
(\mathbf{k a})\end{array}$ \\
\hline IEE1899 & YC7-1 & 2.49 & 10.41 & 1.45 & $3.23 \pm 0.13$ & $57.4 \pm 1.0$ & $17.79 \pm 0.84$ \\
IEE1900 & YC7-2 & 3.21 & 10.88 & 1.67 & $3.67 \pm 0.14$ & $56.8 \pm 2.3$ & $15.46 \pm 0.92$ \\
IEE1901 & YC7-3 & 3.00 & 9.92 & 1.60 & $3.42 \pm 0.13$ & $158.7 \pm 5.7$ & $46.5 \pm 2.6$ \\
IEE1902 & YC7-4 & 3.72 & 11.78 & 1.60 & $3.77 \pm 0.15$ & $348.4 \pm 1.8$ & $92.4 \pm 4.2$ \\
IEE1903 & YC7-5 & 2.39 & 8.31 & 1.60 & $3.06 \pm 0.12$ & $543.3 \pm 2.2$ & $177.6 \pm 7.8$ \\
IEE1904 & YC7-6 & 2.65 & 9.48 & 1.63 & $3.23 \pm 0.13$ & $604 \pm 11$ & $187.1 \pm 8.9$ \\
IEE1905 & YC7-7 & 4.30 & 10.14 & 1.57 & $3.79 \pm 0.16$ & $111.4 \pm 6.1$ & $29.4 \pm 2.1$ \\
IEE1906 & YC7-8 & 3.99 & 11.19 & 1.63 & $3.82 \pm 0.16$ & $166.7 \pm 1.9$ & $43.7 \pm 2.1$ \\
IEE1907 & YC7-9 & 3.51 & 12.38 & 1.63 & $3.76 \pm 0.15$ & $239.2 \pm 6.1$ & $63.6 \pm 3.3$ \\
IEE1908 & YC7-10 & 3.63 & 10.48 & 1.52 & $3.54 \pm 0.14$ & $355 \pm 26$ & $100.3 \pm 8.6$ \\
IEE1909 & YC7-11 & 2.90 & 9.32 & 1.51 & $3.30 \pm 0.13$ & $112.1 \pm 4.2$ & $34.0 \pm 2.0$ \\
IEE1910 & YC7-12 & 3.21 & 9.94 & 1.54 & $3.46 \pm 0.14$ & $163.0 \pm 6.2$ & $47.2 \pm 2.7$ \\
IEE1911 & YC7-13 & 3.00 & 9.84 & 1.63 & $3.41 \pm 0.13$ & $153.8 \pm 8.4$ & $45.1 \pm 3.2$ \\
IEE1912 & YC7-14 & 2.73 & 9.29 & 1.63 & $3.27 \pm 0.13$ & $157.6 \pm 6.4$ & $48.3 \pm 2.9$ \\
IEE1913 & YC7-15 & 2.65 & 9.83 & 1.62 & $3.27 \pm 0.13$ & $257 \pm 28$ & $78.7 \pm 9.1$ \\
IEE1914 & YC7-16 & 2.36 & 9.09 & 1.54 & $3.03 \pm 0.12$ & $303.4 \pm 9.0$ & $100.2 \pm 5.3$ \\
IEE1915 & YC7-17 & 3.44 & 9.99 & 1.54 & $3.50 \pm 0.14$ & $161 \pm 17$ & $46.1 \pm 5.3$ \\
\hline
\end{tabular}

Event 2 happened along f2, resulting in collapse wedge II (Units 6 and 5). Thus Event 2 happened between $63.6 \pm 3.3 \mathrm{ka}$ and $43.7 \pm 2.1 \mathrm{ka}$.

Event 3 happened along f1, resulting in collapse wedge III. Thus Event 3 took place after the formation of Unit 4-b, but before Unit 4-a. The age of Event 3 is constrained to between $29.4 \pm 2.1 \mathrm{ka}$ and $43.7 \pm 2.1 \mathrm{ka}$.

Event 4 resulted in a fault in Unit 4-a and thus took place after the deposition of Unit 4-a (maybe even Unit 3 ), but before the deposition of Units 1 and 2. Thus Event 4 happened between $17.8 \pm 0.8 \mathrm{ka}$ and $29.4 \pm 2.1 \mathrm{ka}$.

\section{CONCLUSIONS}

From this study, it seems that this segment of the Lingwu fault has been relatively active in the past $200 \mathrm{ka}$ with four events in this time period being recognized in the Shuangchagou trench. As the fault is in a highly populated area, intense and large scale scientific studies should be carried out in order to acquire more information on the local geological history. In particular, more data are needed for the development of a tectonic predictive model for the benefit of present and future plans for this region.

\section{ACKNOWLEDGEMENTS}

The paper is funded by CNSF (No: 40972124 and 40921120406) and also the West Light foundation from CAS. Wang X.L. thanks Ann Wintle and Nikos Zacharias for their comments on, and improvement of this manuscript.

\section{REFERENCES}

Chai C, Liao YH, Zhang WX and Xu WJ, 2001. Late Quaternary paleoearthquakes and their rupture features along the Lingwu Fault. Seismology and Geology 23: 15-23 (in Chinese with English abstract).

Gu GX, Lin TH, Shi ZL, Li Q, Lu SD, Chen H, Wu HY, Yang YL and Wang SY, 1989. Catalogue of Chinese Earthquakes 1831 B.C.1969 A.D. Translated by Li Z. and others. Beijing: Science Press: $\mathrm{xi}+872 \mathrm{pp}$

Fattahi M, Nazari H, Bateman MD, Meyer B, Sébrier M, Talebian M, Le Dortz K, Foroutan M, Ahmad Givi F and Ghorashi M, 2010. Refining the OSL age of the last earthquake on the Dheshir fault, Central Iran. Quaternary Geochronology 5(2-3): 286-292, DOI 10.1016/j.quageo.2009.04.005.

Liao YH, Chai CZ Zhang WX and Xu WJ, 2000. The active features and slip rate of Lingwu faults in late Quaternary. Earthquake Research in China 16: 158-165 (in Chinese with English abstract).

Lu YC, Wang XL and Wintle AG, 2007. A new OSL chronology for dust accumulation in the last 130,000 years for the Chinese Loess Plateau. Quaternary Research 67(1): 152-160, DOI 10.1016/j.yqres.2006.08.003.

Rees-Jones J, 1995. Optical dating of selected British archaeological sediments. Unpublished D. Phil. Thesis, University of Oxford.

Zhang YQ, Mercier JL and Vergély P, 1998. Extension in the graben systems around the Ordos (China), and its contribution to the extrusion tectonics of south China with respect to Gobi-Mongolia. Tectonophysics 285: 41-75. 